\title{
CONTROL OF ODONTRIA BY DDT and BHC INSECTICIDES
}

By J. M. KELSEY, Officer in' Charge, Entomological Research Station, Department of Scientific and Industrial Research, Ashburton.

A paper on the subject of grass-grub and subterranean caterpillar control was read at the 1950 Grassland Conference at Invercargill; the work has been continued and the Ashburton Station has issued a pamphlet giving more definite recommendations than in the previous paper. The present paper is confined to control of grass-grubs, but the same treatment will automatically kill porina (subterranean caterpillar or Oxycanus). Though control recommendations are included and will be published in this paper, it is intended to confine remarks to factors that can prevent good control by DDT and BHC. The recommendations are :-

1. For general grazing land or where a pasture life of not more than 2 years is required where grass-grub alone is present use either:

(a) llb of 100 per cent parapara isomer DDT per acre or its equivalent at lower percentages, e.g., $21 \mathrm{~b}$ of 50 per cent ppi ; $41 \mathrm{~b}$ of 25 per cent ppi, etc.

(b) llb of 100 per cent gamma isomer BHC ("Gammexane," Lindane, 666, etc.) per acre or its equivalent at lower percentages. BHC is benzene hexachloride.

2. For high return pastures and seed crops, etc., or where a longer protection is desired, and where both grubs and caterpillar are present use DDT and BHC at $21 \mathrm{~b}$ of 100 per cent per acre.

3. For subterranean caterpillar (Porina) only: (a) $\frac{1}{2} \mathrm{lb}$ of 100 per cent gamma BHC per acre on general grazing land.

(b) llb of 100 per cent gamma BHC per acre on high return areas. 
(c) $21 \mathrm{~b}$ of 100 per cent ppi DDT per acre, since this material, in the first year only, is about a quarter as effective as the same dosage of BHC. It has, however, a better residual effect than $\mathrm{BHC}$ after the first year.

\section{EFFECTIVE PERIOD}

DDT treatment will give good control of:- both grub and caterpillar for two years at the llb per acre rate, and for at least three years at the $21 \mathrm{~b}$ per acre rate if applied carefully. BHC will give good control of grubs for 2 years at the llb per acre dosage, but will not control caterpillars beyond the first year. The above remarks apply to, normal rainfall areas in Canterbury and the Waikato. In years of flooding or exceptionally heavy rainfall or on irrigated areas it may be necessary to treat each year to control the caterpillar with both DDT and BHC. The residual effect against grass-grub, however, should continue to give control up to the 3 years.

Insecticides must reach the soil surface and to ensure this the following rules must be adhered to:

1. Treat close-grazed (not more than lin. long), dry pasture. (By dry I mean of such a nature that the DDT-superphosphate, etc., would not remain on pasture when it is shaken).

2. If pasture is not dry, treat the close-grazed, wet pasture and keep stock off until a rainfall of at least $\frac{1}{2}$ in falling in not more thar. 24 hours washes insecticides on to the ground. If insecticide is applied to damp pasture and allowed to dry there,. it would take from 2 to 3 in of heavy, continuous rain to wash it on to the ground. If it is possible to treat during rain, this would be well worth the extra inconvenience.

\section{TIME OF APPLICATION}

1. Apply as soon as grubs are known to be present. They are actively feeding from December to mid-October and do not cease feeding during winter, so time of application can be fitted in conveniently with other farm duties. If treated superphosphate is used, the best times to apply would be autumn and spring, 
'when full advantage could be derived from the fertiliser. Better results will be obtained if the treated area is rolled afterward to. consolidate loosened turf, and stock should be left off such rolled paddocks to permit re-rooting to occur.

2. Do not apply insecticides when clovers are in bloom or bees; moths, etc., that pollinate them will be killed, and poor seed yields will result .. and honey-production will be affected.

\section{SPEED OF ACTION OF INSECTICIDES}

Speed of action of the insecticides depends on severity of infestation and soil moistures and temperatures. In the South Island visible differences -between treated and untreated areas should be obvious by the end of the second week after treatment where this is applied before mid-April and when grub populations are high. Application during winter gives very little visible result until September, because soil temperatures are too low to permit top growth of pasture; the grubs, however, will be affected and damage will cease.

Dosages ' given above will not kill all grubs, but will prevent measurable damage to pasture. Sampling of treated land often shows that hundreds of grubs remain alive; this need not alarm farmers if pasture shows improvement. The grubs are very difficult to kill at one stage in development, but are affected in some way because the pastures, begin to show recovery from the first week after treatment,.:,

\section{ANIMAL AND PLANT WELFARE}

Removal of stock from treated, wet pasture is to prevent them eating the DDT or BHC before it can be washed on to the ground surface; if stock eat the insecticides, grub control will be disappointing or pre- , vented. Farmers need. have no fears that the DDT and $\mathrm{BHC}$ at the dosages recommended will cause stock ailments if the insecticides are applied as recommended. These insecticides will not adversely affect earthworms or nitrifying bacteria, nor will DDT adversely affect germination of pasture seeds at the dosages recommended. In regard to cereals, DDT can be used'safely at sowing, but BHC in technical or lindane forms should not be used for this purpose. 


\section{METHODS, OF APPLICATION}

Application methods can be divided into two main sections with materials available at present; their advantages and disadvantages are discussed below :

1. Dry Treatments can be applied:

(a) As dusts containing up to 5 per cent ppi DDT or gamma BHC in a filler dust such as talc and applied by a dusting apparatus. This requires special apparatus and would require care in regard to neighbouring insect-pollinated crops, as fine dusts carry for miles even in light breezes.

(b) Mixed with fertilisers ; e.g., the DDTsuper-phosphate and BHC-superphosphate that have been used for the past 3 years. This requires no special implements and is the most practical method for the farmer, since superphosphate is normally applied in any case.

(c) Mixed and sown with the seed., This is a good method if superphosphate has been applied previously, but it involves farm mixing. Only DDT should be used for this purpose and the DDT-seed mix should not be held in storage for longer than a week.

2. Spray Treatments. In theory these could be. applied by -ground apparatus or by aeroplane. Both, for economy, would involve low volumes of solutions or suspensions, but for effectiveness with present types of machinery 500, gallons or more of spray per acre would be required to get the insecticides on to the ground where required for grub control. Suspension sprays with low volumes have the drawback also that there is a probability that the. fine insecticide particles will settle along the spray tubes and booms and cause blockages of these and jets, which have to be very fine to secure even coverage with low volumes. Our work has -shown that 100 gallons of spray per acre are not sufficient with low-pressure apparatus to give maximum grub control when pastures are 2in long or longer. It is possible; though, 
that' low-volume spraying of pasture hard grazed by sheep will give good results with high pressure, low-volume ground sprays. Aerial spraying has not been attempted so far for grub control ; my personal opinion is that such a method will prove not only dangerous. as far as seed crops and honey production are: concerned, but also, almost useless for grub control. It could possibly be of use for control of the surface-feeding subterranean. caterpillar. If any type of spray dries on pasture, it will take at least $2 \mathrm{in}$. of really heavy, continuous rain to dislodge it, and this must fall before stock is permitted to graze such pasture. Low-volume sprays give excellent. results against the caterpillar, but our experience with low-pressure apparatus is that very disappointing results in grub control will be: secured.

\section{'SUMMARY OF METHODS}

DDT and BHC can be applied by two practical methods utilising normal farm machinery and with no. increase in labour. These are the treated superphosphate and treated seed methods. For best results broadcasting should be used with both these methods. in preference to drilling. This is because there are. only $21 \mathrm{~b}$ of effective material in the maximum dosage of DDT and BHC and it is important to get some. particles on to each square inch of ground surface. Seven-inch drills, for example, treat only $1 / 7$ th of the paddock or, in other words, the total area pro-tected against grub - works out at only 1 acre in every 7 acres drilled. It is obvious from this that a very high percentage of grubs will be unaffected by drilledin insecticides. There is another angle to this question; this is that the dosages of DDT and BHC have. been kept at the lowest effective levels not only for economic reasons, but, because high dosages can cause plant and stock ailments. This is particularly noticeable in regard to BHC, which can retard and reduce germination and growth of cereals very considerably, and if the $21 \mathrm{~b}$ dosage which is intended for even distribution over a full acre is concentrated in $1 / 7$ th that area (e.g., in' 7in. drills) there is a strong probability that seed and plants will be adversely affected; this will be even more marked in a drought year.

DDT and BHC are excellent insecticides for grub 
control, but are quite useless if users do not fully understand methods of application, etc. It is not sufficient merely to buy and apply DDT in superphosphate or seed in any old way, as one or all of the following factors can prevent good results.

1. Faulty mixing of DDT with superphosphate or seed will give patchy results. The practice of pouring unmeasured amounts of insecticide into seed or manure boxes should be stopped. Hand mixing with shovels or concrete mixers is just as satisfactory as mixing at fertiliser works, providing it is done thoroughly. As a visual aid to mixing, it would be advisable for suppliers of insecticides to colour them so' that farmers can see whether or not the mix is even. Mixing with damp superphosphate, etc., should be avoided, as this prevents even distribution even though correct amounts of insecticide were used.

2 . Dosages too low: Some farmers guess at area of paddocks or at rates the drills or topdressers are applying. This can result in insecticide being applied at rates too low for good control. Under this heading comes the drilled-in material, because with $7 \mathrm{in}$. drills $6 / 7$ th of the area has received no insecticide at all. Some DDT salesmen have told farmers that where 7in drilling is carried out it is necessary to use only $1 / 7$ th the dosage of insecticide; this is not the case. Farmers should understand that we have kept dosages down as low as is practicable and still give control, and though it is possible in some special cir-

cumstances to deviate from the 1 to $21 \mathrm{~b}$ dosages, this should not be done without discussing it with the Ashburton station.

3. Faulty application of insecticides is the commonest cause of failure of DDT and BHC. There are only two really sound recommendations for treating pasture and these are given earlier in this paper. Treatment of long pasture or in winds should always be avoided. If it is necessary to treat wet pasture, this should always. be shorter than 1 inch and stock must not be allowed to eat it till rain has washed insecticides on to the ground. If it 
is possible to apply DDT-superphosphate, etc., during rain, this would be preferable to application on damp pasture which is then permitted to 'dry.. Half an inch of rain is sufficient to wash insecticides off wet pasture, but not once the pasture has dried with the insecticides on it. Farmers may have to wait. a month or more before rain falls, but they should keep stock off treated pasture until this happens if they want maximum results in grub control. Until more efficient apparatus is developed, spray application is not recommended for general treatment. Similarly spin dressers, blowers, and aeroplane applications are not recommended with present forms of insecticides, as we have found that control is better the closer insecticides are applied to the ground surface. Insecticides give very much better control if broadcast instead of drilling them in. This applies both when mixed with superphosphate and with seed. There have been several cases where high grub populations prevented pasture establishing between treated drills.

4. Management after application can completely nullify care taken under the headings above. This section involves only grazing, but this can result in stock eating nearly all the insecticides if treatments were applied to wet pasture and not washed off before grazing. Though stock will not be affected adversely, poor or no grub control will be the result.

5. Low grub populations may give disappointing results. This is because there is a critical grub Population below which no visible damage is apparent. The critical population varies with soil, climate and pasture cover, and varies from year to year in any given district as rainfall distribution varies. A district's normal rainfall well distributed throughout the year will raise the critical population level, whereas the same amount of rain falling, say, in winter and spring and providing drought conditions in summer and autumn will lower the critical population. In other words an average population of 20 grubs per sq. $\mathrm{ft}$. could. severely injure. pasture under drought 
conditions, whereas the same soil could harbour 40 or more per sq. ft. without showing injury where soil moisture was adequate for vigorous pasture growth. Even though treatment of land with low grub populations gives no visible improvement, such treatment is still well worth while, as it will prevent higher populations building up in subsequent years. There are many paddocks in Canterbury that would have still had excellent pasture if treatment had been carried out 2 years or even a year ago, whereas now they often show up to 90 per cent, loss in pasture cover.

6. Drought conditions can prevent grub control and, if prolonged, could result in complete pasture loss. This is because there is no rain to wash insecticides. into the soil where grubs are active or, where insecticides have been drilled in, to disperse insecticides laterally 'in the soil. Insecticides lie in drills. or on the surface and grubs will not be affected till they come in contact with the insecticides. This results in roots being eaten off up to the insecticide level, which in drills is about lin. deep ; this depth of root system is not sufficient to prevent the pasture drying out from drought effects, even though it cannot be pulled up as for typical grub damage. Drought conditions can prevent good grub control the second year after application, even though excellent control was experienced the first season. This arises where rain the first year washed insecticides in to only lin. or $1 \frac{1}{2}$ in. depth, and, as pointed out 'above, this will not prevent drought loss.

Treated pasture on irrigated land has given consistently good results, and DDT has been used by farmers sufficiently long to make it quite certain that when properly applied to good, irrigated pasture it will be possible to carry 6 to 8 sheep per acre throughout the year in Canterbury, and length of effective life of pasture will be considerably extended.

\section{DISCUSSION}

Q. Do DDT or BHC have any adverse chemical effects on the soil? 
A. The full story is not yet known, but so far the only adverse effects noted have been on the growth of some associated plants, particularly cereals, by BHC. At the small dosages recommended there are no effects on worms or nitrifying bacteria. No investigations have yet been made on $\mathrm{pH}$ changes or other chemical effects, and personally I do not think that at the recommended dosages there are any adverse chemical effects.

Q. Would you please expand on your statement that, at present applications of insecticides by $\mathrm{spm}$ dressers, blower; or aircraft are not recommended. In my district topdressing by air is of great importance.

A. We have investigated these three methods of application, and find that the closer these insecticides are released to the ground the better is the control achieved. DDT is finely ground and drifts away as a fine dust. For aerial topdressing I hope the manufacturers can develop a fertiliser plus insecticide in pellet form.

A farmer. Three years ago my property was topdressed from the air with fertiliser plus insecticide and in general very good results were achieved.

Q. Does the porina move far from its tunnel?

A. Not more than 3in. if pasture growth is plentiful. As the pasture decreases in quantity it increases its range and also constructs other tunnels. 